\title{
Atenção psicológica à mulher em situação de violência doméstica no Brasil: uma revisão integrativa
}

\author{
Psychological care for women in situations of domestic violence in Brazil: an \\ integrative review
}

Helem Cristiane Santos Silva ${ }^{1}$; Mirian Ferreira Brito de Ataíde ${ }^{1}$; Thaís Diniz Santos Moreira ${ }^{1 *}$

${ }^{1}$ Faculdade Anísio Teixeira - FAT, Feira de Santana - Bahia, Brasil, 44032-620, helemcristianesantos@hotmail.com;_ mirianbritofsa@gmail.com; *thaisufrb@gmail.com; https://orcid.org/0000-0001-9652-9547(autora correspondente)

\section{Resumo}

Considerando os danos psicológicos causados pelas diferentes formas de violência sofridas pela mulher e as contribuições da psicologia no sentido de reduzir esses danos, o presente estudo teve por objetivo identificar as possibilidades de intervenção psicológica direcionadas à superação das diferentes formas de violência doméstica sofridas pela mulher, a partir de uma revisão integrativa da literatura. O levantamento bibliográfico foi realizado na base de dados BVS Brasil, considerando apenas artigos publicados após o ano da promulgação da Lei Maria da Penha, ou seja, a partir do ano de 2007 até 2019. Foram selecionados 10 artigos que apresentavam ou propunham algum tipo de intervenção psicológica utilizada na atenção a mulher em situação de violência doméstica, nos quais foram identificadas intervenções de três tipos: grupos reflexivos, plantões psicológicos e atendimentos interdisciplinares.

Palavras-chave: Violência doméstica, violência contra a mulher, intervenção psicológica.

\begin{abstract}
Considering the psychological damage caused by the different forms of violence suffered by women and the contributions of psychology to reduce these damages. The present study aimed to identify the possibilities of psychological intervention aimed at overcoming the different forms of domestic violence suffered by women, based on an integrative literature review. The bibliographic survey was conducted in the VHL Brazil database, considering only articles published after the year of the promulgation of the Maria da Penha Law, that is, from the year 2007 to 2019 . 10 articles were selected that presented or proposed some type of psychological
\end{abstract}


intervention used to care for women in situations of domestic violence, in which interventions of three types were identified: reflective groups, psychological shifts and interdisciplinary care.

Keywords: Domestic violence, violence against women, psychological intervention.

\section{Introdução}

O número de casos de violência doméstica contra a mulher vem crescendo no Brasil. Em pesquisa do DataSenado sobre a violência doméstica e familiar contra as mulheres no Brasil, identificou-se um aumento no número de mulheres que declaram terem sofrido algum tipo de violência doméstica: o percentual passou de $18 \%$, em 2015, para 71\%, em 2017. Também houve aumento no número de mulheres que dizem conhecer alguma mulher que já sofreu essa forma de violência, o percentual foi de 29\% em 2015, para 71\%, em 2017 (BRASIL, 2017).

A violência doméstica contra a mulher é configurada como qualquer ação que lhe cause lesão, sofrimento ou dano, e que ocorra no âmbito da família, do ambiente doméstico, ou de qualquer relação íntima de afeto. Os diferentes tipos de abuso contra a mulher são classificados como: violência patrimonial, violência sexual, violência física, violência moral e violência psicológica. Destas, a mais explícita é a física, ou seja, o ato de provocar lesões corporais provenientes de queimaduras, mordidas, espancamentos, entre outras ações que ponham a integridade física da mulher em risco.

A violência sexual praticada contra a mulher corresponde a toda atividade ou prática sexual realizada sem o seu consentimento, através de mecanismos que anulem sua vontade pessoal, como uso da força, chantagem, ameaça, etc. Já a violência patrimonial constitui a subtração ou retenção de bens da mulher. Como por exemplo, quebrar móveis, rasgar roupas, tomar dinheiro, ou, até mesmo, não pagar pensão alimentícia. A violência emocional ou psicológica, por sua vez, trata-se dos danos causados à competência emocional da mulher, expressos através de ameaças, intimidações, manipulações, dirigidas a ela ou a seus filhos, bem como humilhação, isolamento e agressões verbais, ações que podem influenciar na motivação e na autoestima feminina. A violência moral é entendida como qualquer conduta que configure calúnia, difamação ou injúria (BRASIL, 2006). 
Segundo Rolim e Falck (2017) a violência contra a mulher é historicamente construída e tem por base a naturalização da desigualdade entre os gêneros, ou seja, a criação de uma hierarquia na qual o homem é visto como superior a mulher. Na realidade brasileira, a constituição da figura da mulher se deu com base na subordinação ao homem, o qual aparece como uma figura de poder (SOUZA; FARIA, 2017). Ou seja, a violência doméstica ocorre em um contexto em que a mulher ainda é vista como inferior ao homem, não possuindo os mesmos direitos destes.

Esse cenário começou a mudar a partir de 1970, com o movimento feminista, quando essa violência passou a ser tratada como um problema social. Um marco nessa mudança de cenário foi a promulgação da Lei 11.340/2006, mais conhecida como Lei Maria da Penha, a qual apresenta os mecanismos a serem utilizados para coibir a violência contra a mulher, compondo medidas de proteção e assistência, entre as quais destaca-se o atendimento por uma equipe multidisciplinar, que inclua, além de profissionais jurídicos e da saúde, profissionais das áreas psicossociais. Entre outras atribuições, a equipe é responsável por orientar a mulher em situação de violência doméstica e encaminha-la a outros serviços, quando necessário (BRASIL, 2006).

O atendimento psicológico pode ser uma ferramenta imprescindível no combate a violência doméstica contra as mulheres. De acordo com Silva e Silva (2017), “o suporte psicológico pode propiciar o esclarecimento sobre seu contexto familiar, promovendo uma nova significação do conflito, proporcionando um conforto emocional" (p. 90). Essa ressignificação e esse suporte são fundamentais para que a mulher consiga romper com o ciclo de violência, o que torna a presença do profissional de psicologia indispensável nos espaços de acolhimento a essas mulheres.

De acordo com referência técnica elaborada pelo CFP para atuação junto à mulher em situação de violência, as atividades do psicólogo incluem a identificação dos sinais de violência e a avaliação das condições psicossociais em que ela ocorre, bem como o desenvolvimento de estratégias de superação da mesma (CREPOP, 2013). Ainda de acordo com essas diretrizes, a prática cotidiana nos serviços de atendimento perpassa pelo acolhimento, ou seja, oferecer uma escuta inicial e demonstrar que as demandas dessa mulher estão sendo ouvidas, acolhidas e respeitadas, além de encaminhamentos para os demais serviços da rede intersetorial. 
Diante das estatísticas apontadas e dos danos psicológicos causados pelas diferentes formas de violência sofridas pela mulher, e partindo do pressuposto de que o profissional da psicologia, incluído nesse contexto, tem muito a contribuir no sentido de reduzir esses danos, foi realizada uma revisão integrativa da literatura a partir de um levantamento bibliográfico na base de dados BVS Brasil, em busca de intervenções psicológicas direcionadas à atenção a mulher em situação de violência doméstica, após o ano de publicação da Lei Maria da Penha, ou seja, a partir do ano de 2007 até 2019.

O objetivo foi identificar as possibilidades de práticas do profissional de psicologia junto as mulheres vítimas de violência doméstica, bem como os espaços em que estas práticas ocorrem e a relevância das mesmas. Sendo assim, o presente trabalho pretende responder a seguinte questão: Quais possibilidades de intervenção psicológica, direcionadas à superação das diferentes formas de violência doméstica sofridas pela mulher têm sido apresentadas pela literatura da área?

\section{Metodologia}

Este estudo é uma revisão bibliográfica da literatura do tipo integrativa, uma vez que sua finalidade é realizar uma análise metodológica de estudos que proponham intervenções psicológicas utilizadas na atenção a mulher em situação de violência doméstica, possibilitando, aos profissionais, uma utilização consciente das mesmas (SOUZA et al., 2010). Ou seja, tem por objetivo identificar diferentes formas de atenção psicológica direcionadas à essas mulheres, partindo da hipótese de que pode haver diversas possibilidades de intervenção, as quais podem variam de acordo com o contexto em que forem aplicadas.

Para tal, foi realizada uma pesquisa na base de dados BVS Brasil (Biblioteca Virtual em Saúde - Brasil) utilizando as seguintes palavras-chave: "violência doméstica" and "psicologia". Também foram utilizados os filtros Idioma (Português) e Ano de publicação (a partir de 2007). Esta pesquisa retornou um total de 358 artigos, a partir dos quais, mediante leitura dos títulos e resumos, foi feita uma seleção, baseada nos seguintes critérios: (1) apresentar ou propor algum tipo de intervenção psicológica voltada para mulheres em situação de violência doméstica; (2) ter sido publicado entre os anos de 2007 a 2019; e (3) estar escrito em língua portuguesa. 
Sendo assim, foram excluídos os artigos de outras áreas fora da psicologia, bem como aqueles em que a vítima da violência não era a mulher ou era a mulher fora do contexto doméstico. Também não foram considerados os artigos que, assim como este, travam-se de revisões de literatura ou que apresentavam discussões teóricas sobre o tema, sem apresentar ou propor algum tipo de intervenção, de modo que 10 artigos compuseram a seleção final.

Os artigos foram lidos e analisados, buscando identificar: (1) as propostas de intervenção psicológica apresentadas pelos mesmos; (2) os espaços em que essas intervenções ocorrem; e (3) a relevância das mesmas. A análise desses dados teve caráter qualitativo, uma vez que tais dimensões não podem ser operacionalizadas quantitativamente (MINAYO, 2001). Assim como proposto por Souza et al. (2010), a análise e síntese dos dados obtidos foi realizada de forma descritiva, de maneira a reunir o conhecimento produzido a respeito da temática em questão.

\section{Resultados e Discussão}

Os dez artigos selecionados são apresentados no Quadro 1, composto por título, autores e ano de publicação, além dos principais objetivos e resultados de cada um. Nele pode-se notar que, em seis dos dez artigos (PORTO, 2008; RAMOS E OLTRAMARI, 2010; TIMM et al., 2011; VIZZOTTO ET AL., 2012; FARINHA E SOUZA, 2016; GUIMARÃES E DINIZ, 2018) o objetivo foi apresentar alguma proposta de intervenção, a qual consideram útil para o manejo com mulheres em situação de violência doméstica, de modo que os resultados apontam para a eficácia dessas intervenções.

Enquanto os quatro artigos restantes (BALBUENO, 2011; SILVA ET AL., 2016; ROLIM E FALCKE, 2018; GONSALVES E GONÇALVES, 2019) objetivaram investigar as intervenções voltadas para esse público em específico, realizadas em determinados contextos. Sendo assim, seus resultados constituem um parecer a respeito das limitações e potencialidades dessas intervenções, bem como sugerem mudanças. 
Quadro 1 - Apresentação dos artigos selecionados.

\begin{tabular}{|c|c|c|c|c|}
\hline $\mathbf{N}^{\circ}$ & Título & Autores/ano & Objetivos & Resultados \\
\hline 11 & $\begin{array}{l}\text { Intervenção Psicológica em Abrigo para } \\
\text { Mulheres em Situação de Violência: Uma } \\
\text { Experiência }\end{array}$ & $\begin{array}{l}\text { PORTO, M. } \\
\text { (2008) }\end{array}$ & $\begin{array}{l}\text { Descrever a trajetória da reconstrução da } \\
\text { proposta de intervenção psicológica em } \\
\text { um abrigo para mulheres em situação de } \\
\text { violência intrafamiliar e de gênero. }\end{array}$ & $\begin{array}{l}\text { Foi estabelecida uma nova proposta de } \\
\text { intervenção considerando a temática do } \\
\text { enfrentamento da violência contra a mulher. }\end{array}$ \\
\hline 2 & $\begin{array}{l}\text { Atividade Reflexiva com Mulheres que } \\
\text { Sofreram Violência Doméstica }\end{array}$ & $\begin{array}{l}\text { RAMOS, M. E. } \\
\text { OLTRAMARI, L. } \\
\text { C. }(2010)\end{array}$ & $\begin{array}{l}\text { Relatar uma atividade reflexiva } \\
\text { desenvolvida com um grupo com } \\
\text { mulheres que sofreram violência } \\
\text { doméstica. }\end{array}$ & $\begin{array}{l}\text { Identificou-se que, quanto mais agentes } \\
\text { multiplicadores se mobilizarem para fazer algo, } \\
\text { mais se promove uma sociedade que reflita sobre } \\
\text { as questões relacionadas à violência doméstica. }\end{array}$ \\
\hline 3 & $\begin{array}{l}\text { Investigação sobre atendimento } \\
\text { psicossocial oferecido em delegacias de } \\
\text { defesa da mulher }\end{array}$ & $\begin{array}{l}\text { BALBUENO, B. } \\
\text { (2011) }\end{array}$ & $\begin{array}{l}\text { Descrever o modelo de atendiment } \\
\text { psicossocial realizado em delegacias d } \\
\text { defesa da mulher. }\end{array}$ & $\begin{array}{l}\text { to No que se refere ao modelo, apenas uma } \\
\text { le delegacia, entre todas as investigadas, tem } \\
\text { um atendimento psicossocial estruturado. }\end{array}$ \\
\hline 4 & $\begin{array}{l}\text { Psicologia, Violência contra Mulheres e } \\
\text { Feminismo: em defesa de uma clínica } \\
\text { política }\end{array}$ & $\begin{array}{l}\text { TIMM, F. B. } \\
\text { PERERIRA O. P. } \\
\text { GONTIJO, D. C. } \\
\qquad(2011)\end{array}$ & $\begin{array}{l}\text { Realizar uma articulação entre a escuta } \\
\text { clínica em psicologia e o feminismo. }\end{array}$ & $\begin{array}{l}\text { Explicitou-se a proposta de uma metodologia } \\
\text { engajada e politizada para o atendimento às } \\
\text { mulheres em situação de violência. }\end{array}$ \\
\hline 5 & $\begin{array}{l}\text { Os atendimentos em delegacias da mulher e } \\
\text { as técnicas de intervenção utilizadas com } \\
\text { crianças e adultos }\end{array}$ & $\begin{array}{l}\text { VIZZOTTO M. } \\
\text { M. HELENO, M. } \\
\text { G. V. BONFIM, } \\
\text { T. E. ARIAS, G. } \\
\quad \text { S. (2012) }\end{array}$ & $\begin{array}{l}\text { Discute a escuta e a intervenção imediata } \\
\text { no sentido de mobilizar o sujeito para a } \\
\text { busca de uma atenção psicológica } \\
\text { prolongada - psicoterapia. }\end{array}$ & $\begin{array}{l}\text { Ainda que se possa considerar a influência dos } \\
\text { aspectos sociais e culturais que circundam essas } \\
\text { mulheres, os aspectos subjetivos são aqueles que } \\
\text { devem ser entendidos melhor. }\end{array}$ \\
\hline 6 & $\begin{array}{l}\text { Plantão psicológico na delegacia da mulher: } \\
\text { Experiência de atendimento sócio clínico }\end{array}$ & $\begin{array}{l}\text { FARINHA, M. G. } \\
\text { SOUZA, T. M. C. } \\
\qquad(2016)\end{array}$ & $\begin{array}{l}\text { Problematizar as práticas psicológicas em } \\
\text { uma Delegacia Especializada de } \\
\text { Atendimento à Mulher (DEAM) }\end{array}$ & $\begin{array}{l}\text { Observou-se que o Plantão Psicológico } \\
\text { constituiu-se como uma via para o acolhimento } \\
\text { de sentimentos e emoções vivenciados no } \\
\text { contexto de violência, bem como um espaço para } \\
\text { a (re)organização psíquica. }\end{array}$ \\
\hline
\end{tabular}


...Continuação do quadro 1

7

Mulheres e violência doméstica: relato de experiência num juizado especializado

Práticas em psicologia no atendimento a situações de violência conjugal em dispositivos do Sistema Único de Assistência Social (SUAS)

Impactos do livro de uma mulher vítima na

9 vivência de violência conjugal de outras mulheres

A Psicologia junto aos Centros Especializados de Atendimento à Mulher
SILVA, O. M. A.

ALÍPIO, M. P. P.

MOREIRA, L. E.

$$
\text { (2016) }
$$

ROLIM, K. I

FALCKE, D.

GUIMARÃES, F.L. DINIZ, G. R. S

\section{GOLÇALVES,}

E.N.

GOLÇALVES, H.S. (2019)
Analisar o perfil de usuários (as) Foi possível compreender as características dos atendidos (as) pela equipe sujeitos atendidos pela equipe multidisciplinar, o multidisciplinar no ano de 2014 e papel e prática profissional da Psicologia no problematizar a intervenção ocorrida no âmbito jurídico da violência doméstica, além das mesmo ano. articulações entre as Redes de atenção local.

Conhecer e caracterizar as práticas desenvolvidas por psicólogos diante da violência conjugal em dispositivos do Suas, na região do Vale do Paranhana, RS.

A partir das potencialidades e desafios identificados, propõe-se a realização de intervenções psicossociais embasadas nos pressupostos da Clínica Ampliada.

Compreender os impactos da história de uma personagem/mulher vítima na vivência de violência conjugal de outras mulheres.

Conhecer e discutir o trabalho da psicologia junto aos Centros Especializados de Atendimento à Mulher (CEAMs) no Rio de Janeiro.
Essa proposta de pesquisa-intervenção mostrou seu potencial e utilidade como método de pesquisa e como modelo de intervenção clínica.

Aproximação dos psicólogos que atuam nos centros possibilitou relacionar as práticas da psicologia nestes serviços e desenvolver uma discussão sobre a prática PSI no âmbito dessas políticas públicas.

Fonte: Artigos selecionados/Elaborado pelas autoras (2019).

Os artigos foram caracterizados de acordo com as propostas de intervenção apresentadas ou investigadas pelos autores, o espaço em que estas propostas ocorreram e a relevância das mesmas, conforme apresentado no Quadro 2. 
Quadro 2 - Síntese das variáveis de análise.

\begin{tabular}{|c|c|c|}
\hline $\mathbf{N}^{\mathbf{o}}$ & A proposta de intervenção & O espaço \\
\hline 1 & $\begin{array}{l}\text { Atender as mulheres abrigadas em } \\
\text { Grupo Reflexivo e realizar } \\
\text { atendimento individual às mulheres } \\
\text { que apresentarem essa necessidade. }\end{array}$ & $\begin{array}{c}\text { Abrigo para mulheres em situação de } \\
\text { violência. }\end{array}$ \\
\hline 2 & $\begin{array}{l}\text { Grupo reflexivo de mulheres que } \\
\text { sofreram violência doméstica. }\end{array}$ & $\begin{array}{c}\text { Instituição de apoio a pessoas que } \\
\text { sofreram algum tipo de crime ou de } \\
\text { violência. }\end{array}$ \\
\hline 3 & $\begin{array}{l}\text { Atendimento psicossocial } \\
\text { multidisciplinar }\end{array}$ & Delegacias de defesa da mulher \\
\hline
\end{tabular}

Grupo fundamentado na perspectiva

$$
\text { feminista }
$$

Não especificado

Atendimentos imediatos (plantões)

5 utilizando a entrevista clínica psicodiagnóstica

Orientações e acolhimento, na modalidade de plantão psicológico

(projeto de extensão universitária)
Delegacia da mulher

\section{A relevância}

Foi possível perceber que a proposta de atendimento, fundada na intervenção psicológica mediada pela instituição e considerando o contexto da violência contra a mulher, apontava para resultados mais

$$
\text { positivos. }
$$

O grupo proporcionou às mulheres novas formas de agir e pensar.

Mudanças percebidas através dos seus relatos sobre a forma como conseguiam buscar seus direitos de igualdade em relação aos homens ou como estavam agindo com seus companheiros repensando suas atitudes em relação a eles.

Há um reconhecimento por parte dos profissionais acerca da necessidade de uma atenção diferenciada, entretanto, parecem adaptadas ao modelo disponibilizado pelo Estado, como que acomodadas nesse status quo.

As narrativas evidenciam que a metodologia de atendimento fundamentada na conciliação ou na individualidade da pessoa não atende as demandas de interrupção do sofrimento psíquico dessas mulheres. A criação de salas de psicologia nas delegacias especiais, assim como o amadurecimento das técnicas, constitui um dos aportes mais significativos do sistema e permite o desenvolvimento da atenção nas crises, porém, que ainda temos de caminhar muito em investigações que avaliem esse procedimento a fim de verificarmos sua eficácia.

O serviço de plantão psicológico na DEAM tem-se efetivado como

espaço privilegiado de escuta e acolhimento, favorecendo a instrumentalização da mulher para lidar com a violência e resguardando os direitos das pessoas que procuram a instituição. 
...Continuação do quadro 2

\begin{tabular}{|c|c|c|c|}
\hline 7 & $\begin{array}{l}\text { Atendimento Integrado } \\
\text { Multidisciplinar }\end{array}$ & $\begin{array}{l}\text { Juizado de Violência Doméstica e Familiar } \\
\text { contra a Mulher }\end{array}$ & $\begin{array}{l}\text { A Psicologia nesse campo constrói possibilidades de escuta das relações } \\
\text { de gênero, da subjetividade e do protagonismo dos sujeitos, além da } \\
\text { compreensão da singularidade do contexto social e das vivências } \\
\text { pessoais. }\end{array}$ \\
\hline 8 & Atendimento Interdisciplinar & $\begin{array}{l}\text { Dispositivos do Sistema Único de } \\
\text { Assistência Social (SUAS) }\end{array}$ & $\begin{array}{l}\text { Nesse sentido, o acompanhamento psicossocial pode contribuir para a } \\
\text { abordagem de aspectos relacionais das interações amorosas e familiares; } \\
\text { bem como potencializar fatores de proteção, prevenindo agravos e } \\
\text { facilitando o rompimento do ciclo da violência. }\end{array}$ \\
\hline 9 & $\begin{array}{c}\text { Reflexão grupal sobre o livro "Mas ele } \\
\text { diz que me ama: graphic novel de uma } \\
\text { relação violenta" }\end{array}$ & $\begin{array}{c}\text { Núcleos de Atendimento às Famílias e } \\
\text { Autores de Violência Doméstica } \\
\text { (NAFAVD) }\end{array}$ & $\begin{array}{l}\text { A estratégia metodológica utilizada nesta pesquisa-intervenção criou um } \\
\text { contexto adequado para reflexão sobre a dinâmica conjugal violenta. O } \\
\text { sentimento despertado, a partir da leitura do livro, e a identificação com } \\
\text { a história da personagem, ofereceram uma oportunidade para as } \\
\text { mulheres refletirem sobre suas próprias histórias. }\end{array}$ \\
\hline 10 & Atendimento interdisciplinar & $\begin{array}{l}\text { Centros Especializados de Atendimento à } \\
\text { Mulher }\end{array}$ & $\begin{array}{c}\text { No escopo das devolutivas da pesquisa, considerou-se que o atendimento } \\
\text { é um lugar privilegiado de atuação psi nas instituições, todavia este não } \\
\text { precisa ser um lugar restrito, mas ampliado no que se refere à } \\
\text { diversificação. }\end{array}$ \\
\hline
\end{tabular}

Fonte: Artigos selecionados/Elaborado pelas autoras (2019). 
Quanto aos espaços de atuação, apenas um estudo (TIMM et al., 2011) não especificou o contexto em que a intervenção foi realizada. Nas demais pesquisas, as intervenções foram realizadas em instituições ou órgãos que compõem a rede de atendimento a mulheres vítimas de violência doméstica, vinculados ao sistema único de assistência social. Nestes, a prática do psicólogo tem se apresentada de forma bastante diversa, incluindo atividades clínicas, sociais, educativas, de orientação, de mediação de conflitos, cabendo ao profissional entender o funcionamento de cada um dos setores apresentados e da equipe multidisciplinar que os compõem, para adaptar sua prática de acordo com as características e necessidades em cada um desses contextos (CREPOP, 2013).

No Quadro 3 são apresentados os principais serviços que, de acordo com o Conselho Federal de Psicologia (CFP), englobam a rede de apoio às mulheres em situação de violência doméstica, bem como a função que desempenham dentro da rede.

Quadro 3 - Serviços da rede de apoio às mulheres em situação de violência doméstica e suas funções.

\begin{tabular}{|c|c|}
\hline Serviço & Função \\
\hline Serviços de saúde de modo geral & $\begin{array}{l}\text { São oferecidos acolhimento, orientação e acompanhamento na } \\
\text { internação e no ambulatório; }\end{array}$ \\
\hline $\begin{array}{l}\text { Centros e Núcleos de Referência para } \\
\text { a Mulher em situação de Violência }\end{array}$ & $\begin{array}{l}\text { Acolhimento, o acompanhamento e a articulação da Rede, com } \\
\text { variações de estrutura e atendimento entre as diferentes } \\
\text { localidades }\end{array}$ \\
\hline DEAMs & $\begin{array}{l}\text { Acolhimento, orientação e encaminhamentos a outros serviços da } \\
\text { rede }\end{array}$ \\
\hline Hospitais Gerais & $\begin{array}{l}\text { Acompanhamento durante a internação e também a orientação e o } \\
\text { encaminhamento para outros serviços no momento da alta }\end{array}$ \\
\hline Abrigos & Atendimento e acolhimento às mulheres e seus filhos, quando há \\
\hline CRAS e CREAS & $\begin{array}{l}\text { Atendimentos e encaminhamentos de casos de violência contra a } \\
\text { mulher, crianças e adolescentes }\end{array}$ \\
\hline Serviços educacionais & Atividades educativas de prevenção \\
\hline Coordenadoria da Mulher & $\begin{array}{l}\text { Coordenar ações específicas e articular políticas públicas voltadas } \\
\text { para a defesa da mulher }\end{array}$ \\
\hline $\begin{array}{l}\text { Conselhos Tutelares e Conselhos } \\
\text { Municipais de Crianças e Adolescentes }\end{array}$ & Intercâmbio de denúncias \\
\hline Atendimentos do Poder Judiciário & Acolhimento a partir de procura espontânea \\
\hline Organizações não governamentais & $\begin{array}{l}\text { Desenvolvem atividades voltadas para a promoção social, } \\
\text { cidadania e inclusão produtiva }\end{array}$ \\
\hline
\end{tabular}

Fonte: CREPOP (2013) / Elaborado pelas autoras (2019). 
Nestes serviços, o atendimento psicossocial tem sido a principal alternativa, com ações de atendimento e proteção voltadas para a superação da situação de violência. Nesse sentido, o CFP apresenta como possibilidades a clínica ampliada, a clínica social ou ainda intervenções psicossociais articuladas com as práticas de outros profissionais e serviços (CREPOP, 2013). Como veremos mais adiante, essa perspectiva é notada nos artigos aqui analisados, sobretudo nos quatro artigos que objetivaram investigar as intervenções realizadas em algum desses espaços, visto que a ampliação das ações da psicologia nesses contextos foi apontada como fundamental.

Para a análise das propostas de intervenção apresentadas ou investigadas pelos autores, os artigos foram divididos em três categorias: (1) Intervenção Grupal; (2) Plantão Psicológico; e (3) Atendimento inter ou multidisciplinar. As quais serão discutidas individualmente nos tópicos a seguir, incluindo a relevância das mesmas.

\subsection{Intervenção Grupal}

Em quatro dos seis artigos que tiveram como objetivo trazer uma nova proposta de intervenção (PORTO, 2008; RAMOS E OLTRAMARI, 2010; TIMM et al., 2011; GUIMARÃES E DINIZ, 2018), estas foram realizadas de maneira grupal e tiveram como objetivo promover a reflexão. Porto (2008), por exemplo, que propôs a reconstrução do modelo de intervenção realizado em um abrigo para mulheres em situação de violência, apresenta, como uma das estratégias dessa reconstrução, a formação de um grupo reflexivo para atender as mulheres abrigadas. Neste grupo, que recebeu o nome de Mulheres Unidas Para Vencer e foi bem aceito pelas participantes, foram trabalhados temas relacionados a violência contra a mulher através de dinâmicas e debates.

Algo semelhante foi realizado por Ramos e Oltramari (2010), os quais apresentam o relato de uma atividade reflexiva realizada com um grupo de mulheres vítimas de violência doméstica com o intuito de promover discussões para se pensar novas formas de enfrentamento desta situação. Segundo os autores, através do diálogo as participantes do grupo ensinam e aprendem ao mesmo tempo, desenvolvendo um olhar crítico sobre a realidade e encontrando suporte para transformá-la. 
Timm e colaboradores (2011), por sua vez, propõem a criação de um grupo articulando a escuta em psicologia e o feminismo. Descrito como uma metodologia engajada e politizada de atendimento a mulheres vítimas de violência conjugal, o grupo permite a ressignificação das experiências através de seu compartilhamento e da interação entre elas. Guimarães e Diniz (2018), também apresentam uma proposta de ressignificação da experiência, mas através da reflexão grupal sobre o livro, Mas ele diz que me ama: graphic novel de uma relação violenta, o qual conta a história de uma mulher vítima de violência doméstica, possibilitando a identificação de semelhanças entre as experiências da personagem e as vivenciadas pelas participantes do grupo.

Esse tipo de trabalho representa, de acordo com referência técnica elaborada pelo Conselho Federal de Psicologia, uma intervenção eficaz para a superação da situação de violência, uma vez que o compartilhamento de sentimentos e informações entre as participantes proporciona o desenvolvimento de estratégias de forma coletiva. Nesse âmbito podem ser desenvolvidas atividades como oficinas temáticas, grupos operativos e grupos de reflexão como recursos para trabalhar temas específicos (CREPOP, 2013).

A eficácia dessa metodologia foi verificada nos artigos, sobretudo no sentido de promover a reflexão e o empoderamento da mulher através da discussão de temas como direitos humanos e políticas públicas. Notou-se, também, a ampla participação das mulheres neste tipo de intervenção, geralmente através de encaminhamento realizado em plantão psicológico, que costuma ser o primeiro contanto dessas mulheres com a psicologia, o qual será melhor descrito a seguir.

\subsection{Plantão Psicológico}

Nos demais artigos que objetivaram apresentar formas de intervenção nesse contexto de violência doméstica (VIZZOTTO et al.,2012; FARINHA E SOUZA, 2016), o modelo de intervenção foi o do plantão psicológico. Partindo dessa metodologia, Vizzotto e colaboradores (2012), apresentam uma discussão a respeito dos atendimentos realizados Delegacia Especial de Atendimento à Mulher (DEAM), utilizando entrevista clínica psicodiagnóstica, sobretudo 
com as mulheres em situação de violência, em vista a mobilizar o sujeito na busca por um processo terapêutico prolongado.

Enquanto Farinha e Souza (2016), apresentam uma problematização a respeito da prática psicológica realizada em uma DEAM através de um projeto de extensão universitária, no qual a maioria dos atendimentos foram direcionados a mulheres adultas vítimas de violência doméstica, utilizando a metodologia do plantão psicológico com enfoque psicossocial, ou seja, com base em uma compreensão social, cultural e econômica do problema.

O método do Plantão Psicológico é caracterizado pela realização de uma consulta sem duração predeterminada oferecida no momento exato da necessidade, justamente por esse motivo, ele é mais comum no âmbito das DEAM, nas quais o atendimento deve ser focado no presente e, muitas vezes, prevê o encaminhamento a outros serviços (FARINHA; SOUZA, 2016)

Sua relevância foi apontada nos artigos, sendo descrita como uma importante ferramenta de acolhimento às vítimas no momento de maior necessidade, uma vez que, se houve a denúncia, acredita-se que o conflito atingiu um ponto crítico. Esse primeiro atendimento pode ser realizado por apenas um profissional ou por uma equipe inter ou multidisciplinar, como será abordado a seguir.

\subsection{Atendimento Inter ou Multidisciplinar}

Com relação aos artigos cujo objetivo foi investigar as intervenções já realizadas em determinados contextos de atendimento à mulher vítima de violência doméstica (BALBUENO, 2011; SILVA et al., 2016; GONSALVES E GONÇALVES, 2019), as intervenções avaliadas consistiram em atendimentos multi ou interdisciplinares. Esse tipo de intervenção está de acordo com a Lei Maria da Penha, segundo a qual a assistência às vítimas de violência doméstica deve ser realizada por uma equipe de atendimento multidisciplinar, a qual deve contar com profissionais das áreas psicossocial, jurídica e da saúde, cuja função é, entre outras atividades, realizar orientação e encaminhamentos (BRASIL, 2006).

No entanto, “os psicólogos inseridos na política pública devem sempre estar atentos aos processos de sofrimento instalados nas comunidades, nos territórios onde as famílias 
estabelecem seus laços mais significativos" (PIOVEZAN; MONTEIRO, 2015, p. 6), ou seja, esses profissionais devem buscar modelos de intervenção que abarquem a perspectiva social, tendo em vista que a violência contra a mulher é um produto de construções sociais criadas e legitimadas ao longo dos anos.

Balbueno (2011), por exemplo, descreve o modelo de atendimento realizado em delegacias de defesa a mulher, propondo mudanças para um atendimento psicossocial que seja mais eficaz em promover a saúde física e mental dessas mulheres, promovendo bem-estar e o desenvolvimento de autoestima e autonomia. Silva e colaboradores (2016), por sua vez, relatam as experiências de um estágio em Psicologia realizado junto à equipe multidisciplinar de um Juizado de Violência Doméstica e Familiar contra a Mulher, o qual permitiu uma reflexão acerca das ações da Psicologia nesse contexto.

Segundo as autoras, mais do que auxiliar o judiciário em suas decisões, a Psicologia deve promover reflexões acerca do campo da violência. Já Gonsalves e Gonçalves (2019), trazem uma discussão a respeito da atuação de psicólogos em Centros Especializados de Atendimento à Mulher (CEAMs), também direcionando para a reflexão desta prática. Visto que, embora o estudo tenha identificado uma diversidade nas atividades desenvolvidas, o atendimento individual tem sido a prática predominante, fortalecendo a dicotomia entre individual e social.

Ainda dentro dessa proposta, Rolim e Falcke (2018), apresentam características das práticas, voltadas para casos de violência conjugal, desenvolvidas por psicólogos em dispositivos do Sistema Único de Assistência Social (SUAS) e, mediante a identificação das potencialidades e desafios dessas práticas, sugere uma proposta de intervenção psicossocial baseada na Clínica Ampliada a qual, de acordo com Monteiro (2012), dá ao psicólogo a oportunidade de ampliar seu foco de intervenção, alcançando toda a comunidade, através de terapia comunitária e campanhas socioeducativas.

A Clínica Ampliada aparece como um referencial para a conduta dos profissionais de psicologia envolvidos na rede de apoio às mulheres em situação de violência (CREPOP, 2013) e embora tenha sido explicitamente referenciada em apenas um dos artigos estudados (ROLIM E FALCKE, 2018), nota-se que a tendência de uma prática mais contextualizada aparece na maioria dos estudos descritos anteriormente, ressaltando que, em se tratando de intervenções 
no âmbito da violência doméstica contra a mulher, um problema que perpassa pelo contexto social, esse tipo de intervenção torna-se necessária.

\section{Considerações Finais}

A violência doméstica contra a mulher é um problema social e de saúde pública e, como tal, tem um impacto significativo na sociedade, mas sobretudo na vida de suas vítimas. Desse modo, os psicólogos devem se debruçar sobre esta problemática, buscando compreendê-la, tanto no aspecto jurídico e social, quanto no que diz respeito a saúde mental dessas mulheres.

A presente pesquisa objetivou identificar e compartilhar as intervenções que têm sido realizadas no contexto de atendimento às mulheres em situação de violência doméstica, contribuindo, desse modo, para o desenvolvimento desse campo de atuação, uma vez que a presença do profissional de psicologia tem sido cada vez mais requisitada no mesmo. Esta revisão será especialmente importante para profissionais em início de carreira que busquem se apropriar da temática e das possibilidades de intervenção em Psicologia.

De acordo com os resultados, percebeu-se que as propostas de intervenção consideradas úteis para o manejo com mulheres em situação de violência doméstica, apresentados pela literatura, foram realizadas em diversas instituições e órgãos que compõem a rede de atendimento a mulheres vítimas de violência doméstica, sobretudo em Delegacias da Mulher. Quanto ao tipo de metodologia utilizada, foram identificadas, como principais estratégias, as intervenções em grupo, os plantões psicológicos e os atendimentos inter ou multidisciplinares, as quais tiveram sua eficácia comprovada pelos autores. Entretanto, compreende-se que o número de artigos analisados é muito pequeno para se fazer conclusões mais abrangentes. E aproveita-se a ocasião para sugerir que mais estudos desse tipo sejam realizados.

\section{Referências}

Balbueno, B. (2011). Investigação sobre atendimento psicossocial oferecido em delegacias de defesa da mulher. Psicólogo informação, v. 15, n. 15, p. 69-82.

http://pepsic.bvsalud.org/scielo.php?script=sci arttext\&pid=S1415-88092011000100005

BRASIL. (2006). Lei N. ${ }^{\circ} 11.340$, de 7 de agosto de 2006. Brasília: Senado Federal, 58 p. http://www.planalto.gov.br/ccivil_03/_ato2004-2006/2006/lei/111340.htm 
BRASIL. (2017). Violência doméstica e familiar contra a mulher. Pesquisa DataSenado. Brasília: Senado Federal, 82 p.

https://www12.senado.leg.br/institucional/datasenado/arquivos/aumenta-numero-demulheres-que-declaram-ter-sofrido-violencia

CREPOP. (2013). Documento de referência para atuação dos psicólogos em serviços de atenção à mulher em situação de violência. Brasília: Conselho Federal de Psicologia, 120 p. http://crepop.pol.org.br/wp-content/uploads/2013/05/2013-05-02b-MULHER.pdf

Farinha, M. G. \& SOUZA, T. M. G. (2016). Plantão psicológico na delegacia da mulher: Experiência de atendimento sócio-clínico. Revista da SPAGESP, v. 17, n. 1, p. 65-79. http://pepsic.bvsalud.org/scielo.php?script=sci_arttext\&pid=S1677-29702016000100007

Gonsalves, E. N. \& Gonçalves, H. S. A. (2019). Psicologia junto aos Centros Especializados de Atendimento à Mulher. Psicologia USP, v. 30, p. 1-10. http://dx.doi.org/10.1590/0103$6564 \mathrm{e} 180192$

Guimarães, F. L. \& Diniz, G. R. S. (2018). Impactos do livro de uma mulher vítima na vivência de violência conjugal de outras mulheres. Estudos e Pesquisas em Psicologia, v. 18, n. 1, p. 209-229.

http://pepsic.bvsalud.org/scielo.php?script=sci arttext\&pid=S1808-42812018000100012

Minayo, M. C. S. (org.). (2001). Pesquisa Social. Teoria, método e criatividade. 18 ed. Petrópolis: Vozes, 108p.

Monteiro, F. S. O papel do psicólogo no atendimento às vítimas e autores de violência doméstica. Monografia, Centro Universitário de Brasília - UniCEUB. Brasília, 63 p., 2012. Disponível em: https://repositorio.uniceub.br/jspui/bitstream/123456789/2593/3/20820746.pdf. Acessado em 20 de maio de 2019.

Porto, M. (2008). Intervenção Psicológica em Abrigo para Mulheres em Situação de Violência: Uma Experiência. Psicologia: Teoria e Pesquisa, v. 24, n. 3, p. 369-374.

https://www.scielo.br/pdf/ptp/v24n3/v24n3a14.pdf

Piovezan, P. A. \& Monteiro, C. F. B. (2015). Intervenções do profissional do psicólogo do suas no atendimento à mulheres vítimas de violência doméstica: uma revisão dos últimos 10 anos. Uningá Review, v. 24, n. 1, p. 104-113.

http://revista.uninga.br/index.php/uningareviews/article/view/1665/1277

Ramos, M. E. \& Oltramari, L. C. (2010). Atividade Reflexiva com Mulheres que Sofreram Violência Doméstica. Psicologia Ciência e Profissão, v. 30, n. 2, p. 418-427. https://doi.org/10.1590/S1414-98932010000200015. 
Rolim, K. I. \& Falck, D. (2018). Práticas em psicologia no atendimento a situações de violência conjugal em dispositivos do Sistema Único de Assistência Social (SUAS). Pesquisas e Práticas Psicossociais, v.13, n. 4, p. 1-16.

http://pepsic.bvsalud.org/scielo.php?script=sci_arttext\&pid=S1809-89082018000400004

Silva, O. M. A. et al. (2016). Mulheres e violência doméstica: relato de experiência num juizado especializado. Rev. Polis e Psique, v. 6, n. 3, p.145-165. http://pepsic.bvsalud.org/scielo.php?script=sci arttext\&pid=S2238-152X2016000300009

Silva, G. K. O. M. \& Silva, F. M. S. (2017). M. Atenção psicológica Clínica a mulheres em situação de violência: um estudo fenomenológico de uma experiência formativa. Revista Mangaio Acadêmico, v. 2, n. 1, p. 89-97.

http://periodicos.estacio.br/index.php/mangaio/article/viewFile/2388/1740

Souza, M. T. et al. (2010). Revisão integrativa: o que é e como fazer? Einstein, v. 8, n.1, p. 102106. https://www.scielo.br/pdf/eins/v8n1/pt 1679-4508-eins-8-1-0102.pdf

Souza, T. M. C. \& Faria, J. S. (2017). Descrição dos serviços de psicologia em delegacias especializadas de atendimento às mulheres no Brasil. Avances em Psicologia Latinoamericana, v. 35, n.2, p. 253-265.

http://www.scielo.org.co/pdf/apl/v35n2/1794-4724-apl-35-02-00253.pdf

Timm, F. B. et al. (2011). Psicologia, Violência contra Mulheres e Feminismo: em defesa de uma clínica política. Psicologia Política, v. 22, n. 11, p. 247-259.

http://pepsic.bvsalud.org/scielo.php?script=sci_arttext\&pid=S1519-549X2011000200005

Vizzotto, M. M. et al. (2012). Os atendimentos em delegacias da mulher e as técnicas de intervenção utilizadas com crianças e adultos. Psicólogo informação, v. 16, n. 16, p. 191-197. http://pepsic.bvsalud.org/scielo.php?script=sci_arttext\&pid=S1415-88092012000200010

\section{Direitos autorais (Copyrights)}

Financiamento: Esta pesquisa não recebeu nenhum financiamento.

Conflitos de interesse: Os autores declaram não haver conflitos de interesse.

Aprovação do comitê de ética: Não aplicável.

Disponibilidade dos dados da pesquisa: Todos os dados gerados ou analisados neste estudo estão incluídos no manuscrito ou na seção 'materiais complementares/quando houver).

Contribuição dos autores: Idealização, investigação e execução da pesquisa: SILVA, H. C. S.;

ATAÍDE, M. F. B. de. Condução, revisão e correção do manuscrito: MOREIRA, T. D. S. 